\title{
THE MEANING OF ZEHU IN SPOKEN ISRAELI HEBREW:
}

\section{A CORPUS-BASED ANALYSIS OF ITS INTERJECTIONAL FUNCTION}

Both authors have contributed equally to this work

Leon Shor

Tel Aviv University

shor.leon@gmail.com

Anna Inbar
Tel Aviv University
Inbara9@gmail.com

\begin{abstract}
This paper focuses on a particular use of the item zehu 'that's it' in spoken Israeli Hebrew, in which it functions as a secondary interjection that conveys the meanings of "completion" and "restriction". In light of zehu's morphological makeup - a fusion of the SGM demonstrative $z e$ 'this' and the 3SGM pronoun $h u$ 'he' - the interjectional use is suggested to have originated in the grammaticalization of the clause $z e ~ h u$ 'That's him/that', a clause that is normally used in Israeli Hebrew for the identification of people and objects. Each of the two interjectional meanings conveyed by zehu is suggested to be conceptually linked to the meanings of "wholeness" and "rejection" meanings that are potentially related to the basic identificational function of the clause $z e ~ h u$ 'That's him/that.' The interconnection between the meanings of "completion"/ "restriction" and the meanings of "wholeness"/"rejection" is supported by tendencies in semantic change and by patterns of co-speech gestures.
\end{abstract}

\section{Introduction}

In the literature, interjections are defined as conventional lexical items, characterizable by a bundle of formal and functional features. From a formal perspective, interjections are morphologically invariable particles that do not enter into construction with other word classes, and consequently constitute syntactically and prosodically independent utterances. They can typically be regarded as one-position operators, in that they modify an utterance 
or an utterance-complex but do not typically link two discourse segments. Functionally, interjections mainly encode a wide array of pragmatic meanings, while their lexical meaning is weak. Thus, interjections implement modal and interactional meanings, conveying the speaker's stance with respect to the conveyed message or the recipient, and consequently serve as vehicles for marking agreement, disagreement, and emphasis (Ameka 1992, 2006; Wilkins 1992: 124; Cuenca 2000: 35-37, 2013: 209; Norrick 2011: 250, 2014: 224).

The aim of this paper is to analyze one interjectional function of the phrase zehu 'that's it' in spoken Israeli Hebrew. Morphologically, zehu consists of the masculine singular demonstrative pronoun $z e$ 'this' and the enclitic pronoun $h u$ 'he.' This lexical item, along with its feminine (zohi) and plural (ele/u hem, ele/u hen) counterparts, composes a paradigm of (complex) discourse-deictic demonstratives. The use of these discoursedeictic demonstratives has been documented in Hebrew texts starting from the Rabbinic period, where they were integrated within the structure of the clause, typically as the syntactic subject of a nominal clause, and as such they agreed with the subsequent nominal predicate in gender and number. This use still exists in Israeli Hebrew, albeit only in formal or literary registers, as shown in examples 1 and 2 below: ${ }^{1}$

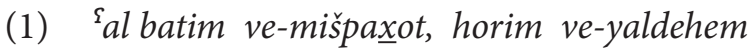
on homes and-families, parents and-their.children 'On homes and families, parents and their children -'

zehu nose sirto ha-ti $i^{\complement} u d i \quad$ šel livyu karmeli this(SGM).he topic(M) his.movie DEF-documentary of Liviu Karmeli 'This is the topic of Liviu Karmeli's new documentary'. (haaretzNEWS1003371:3)

(2) hu kihen rak ₹arba šanim ba-senat he served only four years in-DEF-senate 'He only served four years in the Senate,'

ve-yeš lo me at nisayon benle ${ }^{2} u m i$. and-EXT to.him little experience international. 'and he has little international experience.' 
Leon Shor \& Anna Inbar

Scandinavian Studies in Language, 10(1), 2019 (131-151)

\author{
zohi hitkadmut mehira miday \\ this(SGF).she advancement(F) fast too \\ 'This is too fast an advancement' \\ be ${ }^{\mathrm{S}}$ avur ha-tsibur $\quad \mathrm{ha-}^{\mathrm{T}}$ amerika ${ }^{2}$. \\ for DEF-public DEF-american \\ 'for the American public.' \\ (haaretzNEWS1006924:7)
}

Example 1 describes the topic of a new documentary movie, using an extrapositional sentence with two components: an extra-sentential component - 'On homes and families, parents and their children' - and a sentential component, the subject of which, zehu, points to the extra-sentential component. Based on the information conveyed by the entire sentence, the intended referent of zehu can roughly be understood as 'anything related to family life.' Example 2 consists of two sentences: The first sentence describes two facts about Barack Obama's professional life that hint, in the speaker's opinion, at Obama's relative inexperience, while the second sentence, with zohi as its subject, characterizes the referent of zohi as 'too fast an advancement for the American public.' Based on the information conveyed by these two sentences, the intended referent of zohi can approximately be paraphrased as 'becoming president without having a long political record.' Thus, in both examples, the discourse-deictic demonstratives zehu and zohi point toward previous discourse segments and require the recipient to create a referent out of them (Cornish 2011: 760-761; 2012: 19). Each of these demonstratives is integrated within the nominal clause as the syntactic subject, and is in agreement with the subsequent nominal predicate in gender and number - zehu with nose 'topic(M)', and zohi with hitkadmut 'advancement(F).'

In less formal registers, most typically in spontaneous conversation, the aforementioned use is almost nonexistent. In these registers, zehu has different pragmatic-discursive uses, in which it usually constitutes a syntactically and prosodically independent utterance, and it does not have feminine and plural counterparts. Thus, in conversational language, zehu is a pragmatic marker, with various discourse and modal marking functions (Bardenstein, Shor \& Inbar, forthcoming). In the present paper, we focus on one interjectional function of zehu, in which it can be regarded as a secondary interjection that is a form that originally belonged to another word class, and which has come to be used as an interjection following a process of syntactic reanalysis and semantic change (Cuenca 2000: 40; Ameka 2006: 704). The use to be discussed is related to the meanings of "completion" and "restriction". In such interjectional use, zehu may highlight the completion of some durative state 
or event, possibly consisting of a series of sub-events. This use is demonstrated in example 3 below:

(3)

$$
\begin{aligned}
& \text { sp1 jef lax od ktsat keilu / } \\
& \text { ExT to.you more a.little like / } \\
& \text { 'Do you still have a little bit more (work left)?' }
\end{aligned}
$$

$$
\begin{array}{ll}
2 \quad \mathrm{sp} 2 \quad & (0.6) \text { en } \| \\
& (0.6) \text { NEG.EXT } \| \\
& \text { '(0.6) There is nothing.' }
\end{array}
$$

3

en $\quad \|$

NEG.EXT \|

'There is nothing. no today this already was $\mathrm{DEF}=$ exam $\quad \mathrm{DEF}=$ big $\quad \mathrm{DEF}=$ last $\|$ 'No, today was the last major exam.'

5
zehu $\|$
this.he \|
'That's it.'

6

(0.4) hakol meaxorenu II

(0.4) everything behind.us \|

'(0.4) Everything is behind us.'

7
(0.4) Seni ve $=$ revi $^{2} i \quad z e$ pinats $\|$
(0.4) Monday and=Wednesday this peanuts $\|$
'(0.4) Monday and Wednesday are peanuts (=easy)'.
(Y32_sp2_086, sp1_053-059)

In example 3, the speakers have previously been discussing sp2's upcoming trip to Thailand, and sp2 said that she felt as though she had already started her trip. After sp1 reminds sp2 that she still has some work left to complete (line 1), sp2, who works as an exam supervisor, says that her last big exam has already taken place, and uses the interjection zehu - produced as an independent utterance ending with a falling terminal prosodic boundary - in order to stress that, in her view, her work is definitely complete (lines 
2-5). In this case, zehu seems to function as an intensifier that takes under its scope the idea of completion of sp2's period of work, after that idea was independently communicated. In other words, the interjectional zehu can roughly be paraphrased as 'totally/absolutely/definitely complete.' Note also that the meaning of completion of sp2's work period is further reiterated by her subsequent remarks in which she explicitly says that 'everything is behind us', and characterizes the two remaining exams as 'peanuts' (lines 6-7). In sum, the idea of completion in this example is conveyed through several means, of which the interjectional zehu is only one, contributing to an intensified delivery of the entire message.

Additionally, zehu may have a restrictive interpretation. Example 4 demonstrates such use:

\begin{tabular}{|c|c|c|}
\hline (4) & sp3 & $\begin{array}{l}\text { be=jom. } \int \mathrm{i} j \mathrm{i} \mid \text { efo hajiti / } \\
\text { in=Friday | where I.was / } \\
\text { 'On Friday, where was I?' }\end{array}$ \\
\hline 2 & sp1 & $\begin{array}{l}\text { jom. } \int i f i \mid \text { ve Sabat } \| \\
\text { Friday | and Saturday } \| \\
\text { 'On Friday, and on Saturday'. }\end{array}$ \\
\hline 3 & sp3 & $\begin{array}{l}\text { nasati jakum ve xazara } \mid(0.3) \text { zehu }|| \\
\text { I.drove Yakum and back | (0.3) this.he || } \\
\text { 'I drove to Yakum and back, (0.3) that's it.' } \\
\text { (C1141_1ND_145-150) }\end{array}$ \\
\hline
\end{tabular}

Prior to (4), sp3 expressed his amazement at the high mileage of his car, claiming that he had barely used it during the weekend. He recalls doing a single ride, and immediately restricts its interpretation by means of zehu, which in this case is meant as 'no other ride than the one mentioned' (line 3). In this example, zehu conveys the idea of restriction similarly to the dedicated restrictive particle rak 'only.'

We believe that the study of Hebrew interjectional zehu presents an interesting case for the study of interjections. The path of development from a demonstrative/pronominal element to a secondary interjection is not welldocumented. Secondary interjections are usually thought of as derived from major word classes, most typically nouns (e.g., the English Boy! Man! God! Shit!), verbs (e.g., the English Damn! Fuck!), and phrases (e.g., the English Goddamn! Holy shit! I'll be damned!) (Norrick 2014). In contrast, there is little scholarly discussion of secondary interjections that originated in grammatical 
elements such as demonstratives and pronouns (but see Wilkins 1992, 1995). Related to this is the mechanism through which the meaning of 'completion' or 'restriction' conveyed by the interjectional zehu might have developed. The rise of secondary interjections is usually accounted for by broadening through overinclusion or analogical extension - of the conceptual content of the source lexeme, which results in a new emotional or attitudinal content (Cruz 2017). However, it is far from clear whether broadening can account for the rise of the meanings expressed by the interjectional zehu from its original discourse-deictic use. The reason for this is that deictic elements, such as demonstratives and pronouns, are typically regarded as encoding procedural, and not conceptual, information. This raises the question of how a procedural information can give rise to a conceptual one.

The remainder of this paper is structured as follows: Section 2 will describe the data utilized in this study; Section 3 will discuss the potential development of the meanings of 'completion' and 'restriction' out of a compound demonstrative lexeme, followed by Section 4, which will present further development of the interjectional zehu. Section 5 is a short summary.

\section{Data}

The data for this research were obtained from the Corpus of Spoken Israeli Hebrew (CoSIH) database (<http://cosih.com/english/index.html $>$ ). The $\mathrm{CoSIH}$ database includes recordings of spontaneous Israeli Hebrew conversations that were made in 2001 and 2002. By focusing on naturally occurring conversations, this study takes a 'usage-based' perspective of language by examining how collaborative and situated interactions influence linguistic patterns in everyday conversation. It should be mentioned, however, that the use of recorded data is inherently limited in that it only provides access to the linguistic and para-linguistic dimensions of the interaction, but not to other, no less significant aspects of interaction, such as gaze, gesture, and posture. ${ }^{2}$

There are 64 tokens of $z e h u$ in the CoSIH database, 20 of which can be related to the meaning of completion and restriction. ${ }^{3}$ While most of these tokens $(17 / 20)$ were found to be prosodically independent, being realized in a separate intonation unit, some of them (3/20) were appended to the clause they modify and were realized in a single intonation unit within that clause.

\section{Discussion}

As was shown in (3), the interjectional zehu may contribute to conveying the idea of completion of durative event or state, in conjunction with utterances that describe the completion explicitly. In such a use, zehu is typically produced as an independent utterance ending with a falling terminal prosodic boundary. A similar instance is demonstrated in example 5 below: 


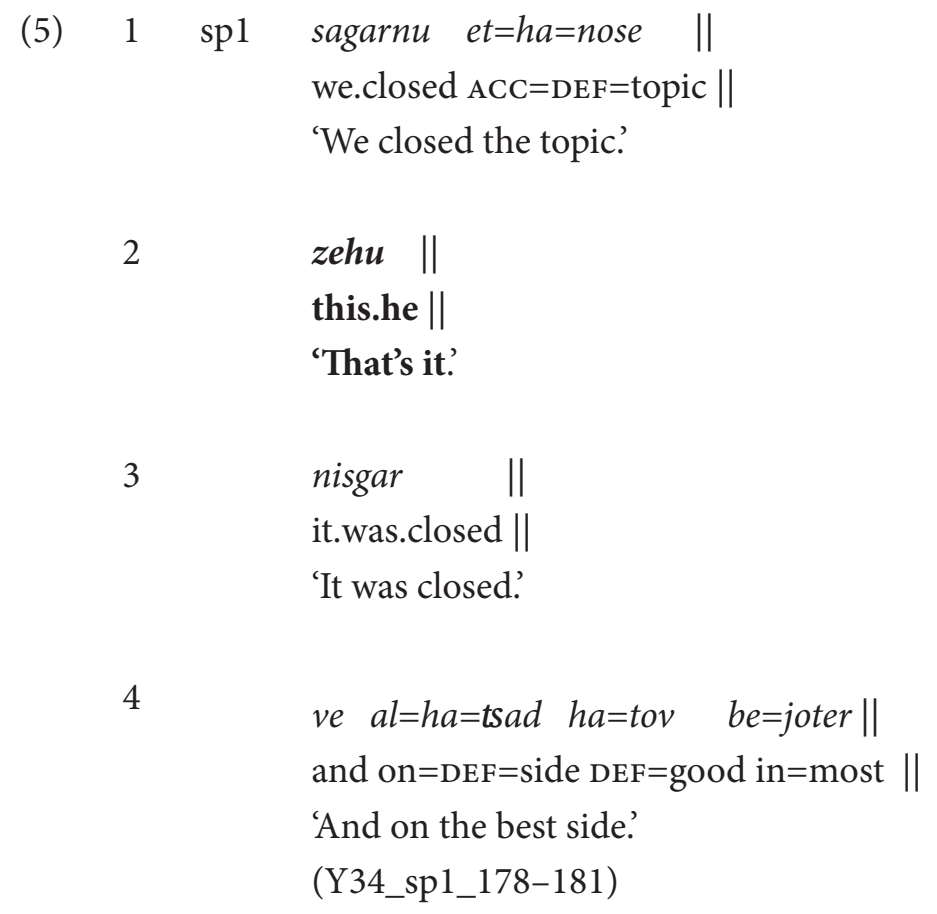

In example 5, sp1 relates to an unpleasant discussion she had with her roommate, and now tells her friend that she and her roommate managed to end the topic. After sp1 explicitly says that they ended the discussion (line 1 ), she uses the interjectional zehu - produced as an independent utterance ending with a falling terminal prosodic boundary - to stress that the discussion is definitely closed (line 2). She then repeats the idea of completion by using the passive verb, nisgar 'it was closed,' which is based on the same consonantal root $(s-g-r)$ as the verb she used before, sagarnu 'we closed,' and thus can be seen as modified repetition (line 3). At this point, although sp1's turn is possibly complete, she adds an 'increment' (Ford et al. 2002) that continues the idea of completion by modifying the manner of completion conveyed previously by the sentence nisgar || 'It was closed,' in this case 'on the best side' (line 4). We can see that similarly to (3), the idea of completion is intensified through several means, of which the interjectional zehu is one.

Example 6 demonstrates a similar instance:

(6) $1 \mathrm{sp1}$ metim latset ita odpaam | dying.PL to.go.out with.her again | 'They're dying to go out with her again, 
2

3

4

5

$$
\begin{aligned}
& \text { ve odpaam | ve odpaam ze aval | } \\
& \text { and again | and again this but | } \\
& \text { and again, and again, but' }
\end{aligned}
$$

(0.8) en $\quad \|$

(0.8) NEG.EXT \|

'(0.8) No'

hi | ata mevin hi |(0.6) hi xotexet ||

she | you understanding.sGm she | (0.6) she cutting.sGF ||

'She, you understand she, (0.6) She ends (lit. cuts)'.

$$
\begin{aligned}
& \text { zehu } \| \\
& \text { this.he } \|
\end{aligned}
$$

'That's it.'

hi xotexet $\|$
she cutting.SGF $\|$

'She ends.'

ma ani jexol laasot $\|$

what I can to.do $\|$

'What can I do.'

(P423_2_sp1_271-280)

Here, sp1 describes his sister's manner of behavior with which he is not satisfied - she tends to end relationships she views as prospectless after a relatively short period of time, even when her partners want to continue going out with her. In order to emphasize his sister's reluctance to continue her relationships, sp1 metaphorically uses the verb xotexet 'cuts' to stress the abruptness of the relationship ending (lines 1-4). He then produces the interjectional zehu as an independent utterance ending with a falling terminal prosodic boundary to stress that the relationship is definitely terminated, and repeats the verb xotexet 'cuts' (lines 5-6). He closes the sequence by expressing his inability to change his sister's behavior, which further stresses the determination of her sister on ending her relationships (line 7). Once again, we can see that the interjectional zehu contributes to the expression of completion or finality, along with additional components.

In some instances, zehu conveys the idea of restriction similarly to the dedicated restrictive particle rak 'only'. Example 7 demonstrates such a use: 
(7) 1 sp2 hajinu xaverim mehatxala \| we.were friends from.the.beginning $\|$ 'We were friends from the beginning.'

2

aval | lo jatsanu harbe || but | NEG we.went.out a.lot || 'But we didn't go out a lot.'

3

mamas lo $\|$

totally NEG \|

'Definitely not.'

4

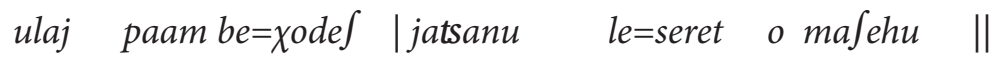
maybe once in=month | we.went.out to=movie or something || 'Maybe once a month we went out for a movie or something.'

5

$z e h u$

this.he \|

'That's it.'

6

$$
\begin{aligned}
& \text { lo | klum || } \\
& \text { NEG | nothing || } \\
& \text { 'No, nothing (else).' } \\
& \text { (P423aND_1035-1043) }
\end{aligned}
$$

Prior to (7), sp2 has been talking about his relationship with his ex-girlfriend, stressing that it was important for him that she pass her matriculation exams, and that he help her prepare for the exams. Here, he further emphasizes his description by saying that although they were a couple at the very beginning of their relationship, they did not go out a lot, implying that the main objective at that point was preparing for matriculation exams (lines 1-3). To emphasize the infrequency of their outings, he restricts it to going to see a movie once a month, and further emphasizes it by means of zehu, produced as an independent utterance ending with a falling terminal prosodic boundary (lines 4-5). The restriction in this case is meant as 'no more than once a month.' In contrast to the dedicated restrictive particle rak 'only', which typically prefaces the element it modifies, and requires the speaker to express the idea of restriction prior to the restricted element, using $z e h u$ as a restrictive marker enables the 
speaker to add the idea of restriction in retrospection, possibly in a separate utterance. In this example, the restrictive interpretation is also supported by the subsequent negative utterance (line 6). Although this utterance does not explicitly mention what exactly is being negated here, it seems to reject any potential counterclaims that may weaken sp2's overall position, namely of going out more frequently than he had previously admitted (Shor forthcoming).

The preceding examples show that the erstwhile compound lexeme $z e h u$, consisting of the demonstrative pronoun $z e$ 'this' and the enclitic pronoun $h u$ 'he', has come to be used in Israeli Hebrew conversation as a secondary interjection, denoting the completion of a durative or continuous event that possibly consists of a series of sub-events. Additionally, zehu may convey the idea of restriction, indicating that only items uttered are relevant, and not others. A question naturally arises touching upon the mechanism through which the meaning of completion or finality, and subsequently that of restriction and exclusivity, might have developed out of a compound of two deictic elements, each of which does not encode any conceptual meaning. Such a development, we believe, cannot be explained by the account of semantic broadening according to which the original concept denoted by the source lexeme is broadened (for expressive means) to a new ad-hoc concept that denotes some emotion, feeling or attitude that is related to, or is the consequence of, what the initial concept denoted (Cruz 2017). Although semantic broadening seems to be able to account for the development of secondary interjections such as Fuck! or Hell! from the corresponding content words, it is far from clear whether it can account for the rise of the meaning of completion, and of the other derivative meanings, expressed by the interjectional $z e h u$, from its original deictic use.

Before we motivate this type of change, it is worth mentioning that the path of development whereby demonstratives evolve into interjections has rarely been documented in the cross-linguistic literature on demonstratives. Diessel (1999: 154), for example, only briefly mentions that interjections and discourse markers may evolve from deictics, and Heine \& Kuteva (2002: 319320) do not mention interjections as a potential grammaticalization target of demonstratives. The most explicit suggestion regarding the relationship between deictics and interjections was put forward by Wilkins (1992, 1995), who proposed to view interjections as a subtype of deictic elements, alongside the more standard members, such as pronouns and demonstratives. One of the arguments for such a view is the observation that various deictic forms may be the source of interjections, or may be used on their own as interjections. For example, the English There! is roughly paraphrased by Wilkins as 'See, I told you so' or 'Just as I expected,' and That's that! is said to be used to terminate any further discussion of a particular matter, or to indicate that some particular matter or event is settled and has come to its natural conclusion (Wilkins 1995: 370). This subgroup of secondary interjections that evolved from deictics or 
demonstratives might be termed 'demonstrative interjections', to borrow a term used by Wang \& Cao (2014) in their description of a group of demonstratives with interjectional functions that are used in several dialects of Mandarin Chinese. The demonstrative interjections described by these authors are used as a response to a preceding utterance, signaling the location of an object in the immediate speech context, and they may convey an overtone of impatience or hurriedness on the part of the speaker. The analysis presented by the authors suggests that these demonstratives acquired their interjectional status through the grammaticalization and lexicalization of the elliptical forms of rhetorical questions containing the demonstratives. The authors go on to suggest that demonstrative interjections might constitute a new type of demonstratives in human languages, resulting in the need to revise existing classifications of demonstratives.

In the case of zehu, we suggest it is the grammaticalization of the minimal clause $z e ~ h u$ 'That's him/That's that' that possibly gave rise to the meanings of completion and restriction. This minimal clause is an instantiation of the identificational construction $z e+N P$, a construction that serves as the basic resource available in Israeli Hebrew for naming people, objects, states, and events. It is usually accompanied by a pointing gesture, as well as by prosodic prominence of the NP. In using this construction, a speaker can direct the recipient's attention to a previously non-attended person or object that the speaker considers to be of relevance for the recipient, and designate it by means of the NP. The NP may be realized by a proper name, a description, or - as is the case of $z e h u$ - by a pronoun.

Crucial to our argument is the connection between the function of identification, through deictic pointing and nominal designation (henceforth IDENTIFICATION), and two related conversational implications - construing the pointed-to referent as a unified whole (henceforth wHoleness) and rejection of other alternatives (henceforth REJECTION). ${ }^{4}$ The link between IDENTIFICATION and REJECTION can be motivated by the assumption that identification of an unfamiliar person or object can be conceptually treated as the rejection of other potential referents in the speech situation, as well as of other potential names for that particular referent. So, in uttering ze hu 'That's him/That's that' in relation to a person, the speaker may be heard as saying, 'That's him and not others.' In addition, the link between IDENTIFICATION and WHOLENESS can be motivated by the assumption that identifying a referent construes it as a single whole, and not as a multitude of sub-components of which it may consist. What is more, there seems to be a conceptual link between REJECTION and WHOLENESS - construing a referent as a unified whole can be envisioned as rejecting elements that do not belong to that whole. If we are correct in our assumption that IDENTIFICATION can imply WHOLENESS and/or REJECTION, then it is plausible to assume that the two interjectional meanings 
conveyed by zehu - completion and restriction - have developed precisely out of these inferences/meanings.

In the following two subsections we provide evidence to support our proposal, according to which REJECTION and/or WHOLENESS can be linked to the meaning of RESTRICTION (Section 3.1) on the one hand, and to the meaning of COMPLETION (Section 3.2) on the other.

\subsection{RESTRICTION as REJECTION and/or WHOLENESS}

That RESTRICTION is linked to REJECTION and/or WHOLENESS is reflected in the cross-linguistically common sources of exclusive/restrictive particles, comparable to the English only - the numeral 'one,' privative notions, and restrictive negative constructions (König 1991: 159; Heine \& Kuteva 2002: 333). Whole is reflected, for example, in the English only, alone, Germam einzig, allein, erst, Latvian viens, viena 'only, one, and Yoruba kàn 'only' (cf. kan 'one'). REJECTION is reflected in restricted negation constructions, such as the French ne...que, the Italian non...che, the German nur, and the Dutch maar. Privation, or an absence of some quality or attribute, may also give rise to exclusive/restrictive particles - the English merely ( $<$ Latin merus 'unmixed'), the Hawaiian wale 'alone, only, without payment/cause', and Modern High German echt (< Old High German eckerodo 'poor, deficient').

Additional evidence for the connection between RESTRICTION and REJECTION comes from the study of gestures accompanying Hebrew speech. Hebrew speakers were found to accompany the restrictive particle rak 'only' with gestures that were usually associated with negation (Inbar \& Shor 2017; Inbar \& Shor forthcoming). ${ }^{5}$ Two such instances are shown in (8) and (9), prior to which the speaker described how, after being raised in a strict religious community, she realized the things she had been told were not necessarily true, leading her to find her own way of believing in god:

(8) 1 sp1 jef rak elohim |ve jef kod mesujam $\mid$ ExT only god | and ExT code specific | 'There is only god, and there is a specific code,' that is how you should dress, it is forbidden to sit near boys.'

(9) 1 sp1 ha=elohim ha=xada hu elohim ohev | $\mathrm{DEF}=$ god $\mathrm{DEF}=$ new he god loving | 'The new god is a loving god,' 


$$
\begin{aligned}
& \text { zot rak ahava | } \\
& \text { this.sGF only love | } \\
& \text { 'this is only love.' }
\end{aligned}
$$

In (8), the speaker describes a series of axioms she was told while growing up, the first of which is that 'there is only god.' This utterance is accompanied by a headshake gesture, realized as multiple swings of the head. Headshakes are usually coordinated with negation and rejection, and in the example discussed may invoke the interpretation 'There is only god, and nothing else.' Shortly after the excerpt presented in (8), the same speaker produces the utterance in (9), in which she says that in contrast to the image of a god that dominated her religious upbringing, one that rewards the good and punishes the bad, she now chooses to believe in a loving god. The loving character of her newfound god is further highlighted by means of the restrictive utterance zot rak ahava 'This is only love', which is accompanied by a headshake gesture, realized as multiple swings of the head. As in (8), this gestures makes visible the 'and nothing else' interpretation, an interpretation that is only implied on the first utterance. These two examples, we suggest, indicate the close conceptual affinity that exists between the domains of RESTRICTION and REJECTION.

\subsection{COMPLETION as REJECTION and/or WHOLENESS}

Evidence for a conceptual link between COMPLETION and REJECTION comes from diverse sources. On an intuitive level, a completed event typically implies that it is not in progress anymore, or that no additional actions are required in order to terminate it. Accordingly, one would expect that the domain of COMPLETION in language would overlap with the domain of REJECTION. As in the case of RESTRICTION, a more concrete evidence for the link between the two domains comes from gestural behavior. In spoken Hebrew, lexemes denoting completion may be accompanied by various co-speech gestures that are typically associated with negation (Inbar \& Shor 2017; Inbar \& Shor forthcoming):

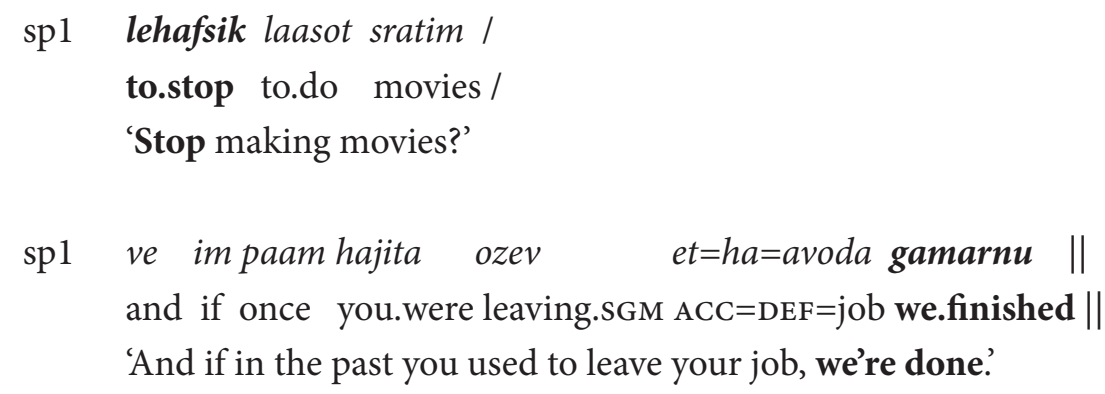


In (10), the speaker moves his left hand from the center of his body to the periphery co-expressively with uttering lehafsik 'to stop'. In (11), the speaker lifts both of his hands up, with the palms vertically oriented, co-expressively with uttering gamarnu 'we finished.' Since both of these gestures are typically associated with utterances that include grammatical negation, it seems plausible to assume that there is some conceptual affinity between the domains of COMPLETION and REJECTION.

At the same time, there also seems to exist a conceptual link between the domains of COMPLETION and WHOLENESS. A terminated event can be conceptualized as a completed whole. The internal composition of that event is backgrounded, whereas its outer boundaries are foregrounded. It should come as no surprise that the domains of COMPLETION and WHOLENESS indeed intersect on various linguistic levels.

One manifestation of WHOLENESs in the grammatical systems of languages is universal quantification, expressed by collective quantifiers (e.g., the English all) and distributive quantifiers (e.g., the English every). This connection is most conspicuously manifested in the fact that, at least in IndoEuropean languages, collective quantifiers generally originate in adjectives meaning 'whole' (Haspelmath 1995). In turn, universal quantification has been linked by various scholars to aspectual notions of completion and completeness. Huber \& Schapper (2014), for example, show that in three related Papuan languages - Bunaq, Kamang, and Makalero - universal quantification and aspectual notions of completion and completeness show various degrees of overlap. This overlap is reflected in deploying a single morpheme for expressing universal quantification on the one hand, and aspectual distinctions on the other. In Bunaq, for example, the same lexical item, - $a^{2} a l$ 'be finished,' may be used to denote the termination of an event, the high degree of a state, or be used as a collective universal quantifier.

Moreover, from a pragmatic perspective, collective quantifiers in various languages are frequently used with the intent to stop some course of action or to describe the end of an action. These include, for example, the English that's all, the Russian $8 c \ddot{e}$, the French c'est tout, and the Estonian kõik. Consequently, if every single one of the sub-actions comprising a specific event has been performed, that event can be regarded as concluded or terminated (cf. Pajusalu 2008: 1957).

\subsection{Interim summary and discussion}

Subsections 3.1 and 3.2 provided evidence to support our proposal, according to which REJECTION and/or WHOLENESS can be linked to the meaning of RESTRICTION on the one hand, and to the meaning of COMPLETION on the other. The proposed path of development is schematically illustrated in Figure 1 below: 
IDENTIFICATION

RESTRICTION

RESTRICTION

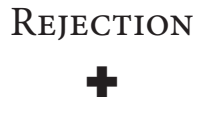

WHOLENESS

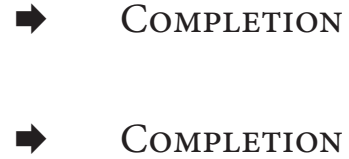

Figure 1

Having established the conceptual link between REJECTION and/ or WHOLENESS to the meaning of RESTRICTION on the one hand and to the meaning of COMPLETION on the other, we propose that RESTRICTION and COMPLETION have been semanticized as a stable component of zehu's meaning, accompanied by several morphosyntactic and semantic changes that are typically attributed to grammaticalization. These changes, as summarized by Brinton (2007: 62), include decategorialization, change from major (open) to minor (closed) word class, freezing of form, desemanticization or semantic 'attrition,' shift from referential (propositional) to non-referential (pragmatic or procedural) meaning, conventionalization of invited inferences, subjectification, divergence, layerin, and persistence (see also Hopper 1991; Lehmann 1995; Traugott 1995a, 1995b; Hopper \& Traugott 2003). The components of the pragmatic particle zehu 'That's it' - the demonstrative pronoun $z e$ 'this' and the enclitic pronoun $h u$ 'he' - are decategorialized, losing their characteristics such as their ability to be inflected according to number and gender. Thus, the particle zehu is frozen in the masculine singular form, and reflects both morphological bonding and phonological attrition, tending to be reduced to $z e u$. Moreover, as a pragmatic particle $z e h u$ is desemanticized, it loses its original identificational meaning and assumes a less concrete and subjective meaning of COMPLETION and RESTRICTION. At the same time, zehu exhibits 'divergence' in that the utterance $z e h u$ continues to be used as a free syntactic resource for directing the recipient's attention to a previously nonattended person or object that the speaker considers to be of relevance for the recipient.

\section{Lexicalization of $z e h u$}

In this section, we wish to present an additional use of zehu that represents a further development of the interjectional zehu. In this use, zehu seems to have lexicalized into a lexeme with the meanings of 'enough, done, complete' and 'only, merely', and it accordingly participates in the clausal structure, typically as a predicate. In example 12, zehu is in embedded position, as a complement of a speech verb - a position that is said to be disfavored for interjections (Wharton 2003). 


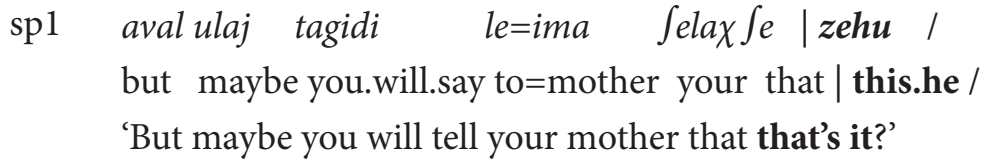

In (12), sp1 addresses his girlfriend regarding her mother's prohibition that they sleep in the same bed. He suggests that maybe it is time to tell her mother that 'that's it', meaning that it is time to end this prohibition. In this case, $z e h u$ doesn't modify any utterance but rather contributes to the propositional content of the utterance. Here, zehu is following the particle $\int e$ 'that', which means that it has its own predicative value (Inbar 2016).

In examples 13 and 14, zehu participates in the syntactic structure of coordination.

\begin{tabular}{|c|c|c|}
\hline & $\mathrm{sp} 2$ & $\begin{array}{l}\text { (0.6) aval ani maamina Se ani epage ita | } \\
\text { ( } 0.6) \text { but I believing.sGF that I I.will.meet with.her } \\
\text { '(0.6) But I believe that I will meet her', }\end{array}$ \\
\hline 2 & & $\begin{array}{l}\text { aval kama jamime } \| \text { ve zehu } \| \\
\text { but few days uh } \| \text { and this.he } \| \\
\text { but for a couple of days, uh. And that's it.' } \\
\text { (Y32_sp2_227-229) }\end{array}$ \\
\hline 1 & sp1 & $\begin{array}{l}\text { aval ma hu asa kol ha=| jamim haele }|| \\
\text { but what he he.did all } \mathrm{DEF}=\mid \text { days these }|| \\
\text { 'But what did he do all these days?' }\end{array}$ \\
\hline & & $\begin{array}{l}\text { Saxav b=a=bajit ve zehu / } \\
\text { he.lay.down in=DEF=home and this.he / } \\
\text { 'Lay down at home and that's it?' }\end{array}$ \\
\hline
\end{tabular}

In (13), sp2 says that she intends to meet a particular friend during her trip in Thailand, but then restricts the scope of her intention to several days. The restriction is expressed by $z e h u$, produced as an independent utterance following the particle $v e$ 'and.' The restriction in this case is meant as 'no more than three days.' In (14), zehu is not even prosodically independent, but the entire coordination construction is produced in the same intonation unit. Here, sp1 asks about her recipient's father's daily routine while he was suffering 
from back pain. She provides a candidate activity, lying down at home, but immediately restricts its interpretation by means of zehu, which in this case is meant as 'no activity other than lying down at home.'

In (15), the lexicalized nature of zehu as an indication of completion is made even more prominent.

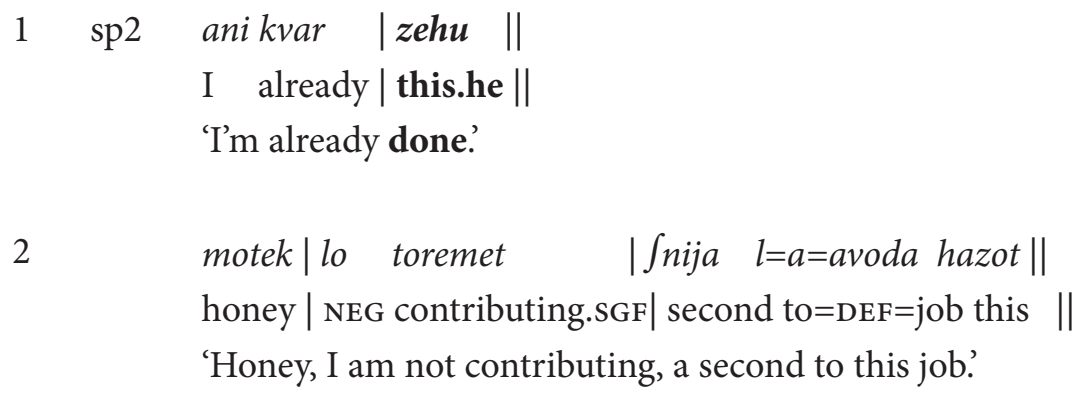

(OCD_1_sp2_064-068)

In (15), sp2 expresses discontent with her workplace, saying that she no longer wishes to put an effort into her job. She begins her complaint with the clause ani kvar |zehu || 'I'm already done', in which zehu functions as the predicate, indicating that $\mathrm{sp} 2$ has finished or completed some activity. The ensuing utterance clarifies the nature of that activity, which can be paraphrased as 'sp2's ongoing readiness to put an effort into her work.'

\section{Summary and prospects}

The corpus-based analysis conducted in this paper has shown that in spoken Israeli Hebrew, the phrase zehu 'that's it' often functions as an interjection that conveys the meanings of COMPLETION and RESTRICTION, in conjunction with other elements in its neighboring context. In light of the morphological makeup of $z e h u$ - a fusion of the masculine singular demonstrative pronoun $z e$ 'this' and the enclitic pronoun $h u$ 'he' - it was suggested that in these occurrences zehu constitutes a secondary interjection that has potentially originated in the grammaticalization of the minimal clause $z e h u$ 'That's him/that.' It was argued, however, that the emergence of these interjectional functions cannot be attributed to the broadening of the conceptual content of the source lexemes, since the source lexemes are, in the case of zehu, a demonstrative and a pronoun - forms that originally encode procedural, and not conceptual, information.

Instead, the paper proposed that each of the two interjectional meanings conveyed by zehu - COMPLETION and RESTRICTION - can conceptually be traced to the meanings of WHOLENESS and REJECTION, meanings that were suggested to be related to the basic identificational function of the minimal clause $z e ~ h u$ 'That's him/that.' Consequently, it was argued that the meanings of 
RESTRICTION and COMPLETION have been semanticized as stable components of zehu's meaning, accompanied by morphosyntactic and semantic changes. Furthermore, it was shown that the procedural meanings of the interjectional $z e h u$ have been lexicalized, and, as such, can participate in the clausal structure, typically as a predicate.

To conclude, the development path described in this paper - from a demonstrative/pronominal element to a secondary interjection and to a lexeme encoding the procedural meaning of the interjection - is not welldocumented in the existing literature (but see Wilkins 1992, 1995). Therefore, we believe it would be particularly advantageous to examine if, and how, this path is manifested cross-linguistically. Such an examination might include, among others, a survey of interjectional meanings that might arise from demonstrative/pronominal elements. Yet another area for future research could be the examination of co-speech gestures that accompany various interjections. According to Wilkins (1992: 134), for instance, deictic gestures may be built into, or may accompany, interjections. In this respect, it would be beneficial to examine what types of co-speech gestures may accompany interjections, and how the meaning of a particular interjection interacts with that of its accompanying gesture. Taken together, these potential lines of research will undoubtedly contribute to a better understanding of interjections.

\section{Notes}

1 These examples were extracted from The Haaretz Corpus, which contains articles from the Haaretz daily newspaper from 2008. The corpus is available at $<\mathrm{http}$ :// hebrewcorpus.nmelrc.org>.

2 In fact, gestural behavior can often provide support for a particular linguistic analysis. This issue is touched upon in Section 3.

${ }^{3}$ Other tokens of zehu function as textual discourse markers that mark the end of a discourse segment, or as interpersonal discourse markers that index various stances. These uses will not be discussed in the present paper. See Bardenstein, Shor \& Inbar (forthcoming).

4 We follow the convention in Conceptual Metaphor Theory (Lakoff and Johnson 1980) and Lexical Typology (Vanhove 2008) to use small capitals for indicating abstract conceptual domains.

5 The examples were taken from a corpus of TV interviews on various topics. See Inbar \& Shor 2017 and Inbar \& Shor forthcoming. 


\section{Appendix - Transcription and glossing conventions}

1. Transcription is usually broad phonetic, with some attention to the phonological system. Phonological input is added mainly in the representation of $/ \mathrm{h} /$, which is omitted in most environments in contemporary spoken Hebrew, and in the representation of some of occurrences of $/ \mathrm{j} /$, which may also elide in certain environments. For typographic and reading convenience, the rhotic phoneme, which in standard Israeli Hebrew is uvular, is represented as $r$; the mid vowels are represented as $e$ and $o$, although their prototypical respective pronunciations are lower.

2. Glossing follows, mutatis mutandis, the Leipzig Glossing Rules (available from http://www.eva.mpg.de/lingua/resources/glossing-rules.php).

3. Transcription follows the system used in $\mathrm{CoSIH}$, as summarized below:

$\begin{array}{ll}\mid & \begin{array}{l}\text { minor boundary } \\ \text { major boundary } \\ /\end{array} \\ -- & \text { major boundary with 'appeal' tone } \\ \text { fragmentary (truncated) } \\ - & \text { truncated word } \\ (0.5) & \text { pause (measures in seconds) } \\ <\text { non-verbal }> & \text { non-verbal sounds }\end{array}$

\section{References}

Ameka, Felix (1992). Interjections: The universal yet neglected part of speech, Journal of Pragmatics 18, 101-118.

Ameka, Felix (2006). Interjections, in: Brown, K. (ed.), Encyclopaedia of Language and Linguistics, 743-746. Amsterdam: Elsevier.

Bardenstein, Ruti, Shor, Leon \& Anna Inbar (forthcoming). Zehu 'that's it' as a discourse marker in spoken Israeli Hebrew, Hebrew Linguistics [Balshanut Ivrit] (in Hebrew).

Brinton, Laurel. (2007). The development of I mean: Implications for the study of historical pragmatics. Methods in Historical Pragmatics. Eds. Susan M. Fitzmaurice and Irma Taavitsainen. Berlin and New York: Mouton de Gruyter, 37-77.

Cornish, Francis (2011). 'Strict' anadeixis, discourse deixis and text structuring, Language Sciences 33(5), 753-767.

Cornish, Francis (2012). Micro-syntax, macro-syntax, foregrounding and backgrounding in discourse - when indexicals target discursively subsidiary information, Belgian Journal of Linguistics 26, 6-34.

Cruz, Manuel Padilla (2017). On the origin and meaning of secondary interjections: A relevance-theoretic proposal, in: Piskorska, A. and Wałaszewska, E. (eds), Applications of Relevance Theory: From Discourse to Morphemes, Newcastle upon Tyne: Cambridge Scholars Publishing, 299-326.

Cuenca, Josep M. (2000). Defining the indefinable? Interjections, Syntaxis 3, 29-44. 
Cuenca, Josep M. (2013). The fuzzy boundaries between discourse marking and modal marking, in: Degand, L., Cornillie, B. and Pietrandrea, P. (eds), Discourse Markers and Modal Particles: Categorization and description [Pragmatics \& Beyond New Series 234], 191-216.

Diessel, Holger (1999). Demonstratives: Form, Function and Grammaticalization, John Benjamins Publishing.

Haspelmath, Martin (1995). Diachronic Sources of 'All' and 'Every', in E. Bach, E. Jelinek, A. Kratzer, and B.H. Partee (eds.), Quantification in Natural Languages, pp. 363-382. Kluwer, Dordrecht.

Heine, Bernd \& Tania Kuteva (2002). World Lexicon of Grammaticalization, Cambridge University Press.

Hopper, Paul J. (1991). On some principles of grammaticization, in: Traugott, E. and Heine, B. (eds), vol. 1, 17-35.

Hopper, Paul J. \& Elizabeth Closs Traugott (2003). Grammaticalization (2nd ed.), Cambridge: Cambridge University Press.

Huber, Juliette \& Antoinette Schapper (2014). The relationship between aspect and universal quantification; Evidence from three Papuan languages from Timor and Alor, in: Klamer, M. and Kratochvíl, F. (eds), Number and Quantity in East Nusantara, Canberra: Asia-Pacific Linguistics, 152-169.

Inbar, Anna (2016). Is Subordination Viable? The Case of Hebrew $\int \epsilon$ 'that', CHIMERA, Romance Corpora and Linguistic Studies 3, 287-310.

Inbar, Anna \& Leon Shor (2017). Negation across Modalities in Spoken Israeli Hebrew - From Verbal to Gestural Communication, 50th Annual Meeting of the Societas Linguistica Europaea (SLE), University of Zurich, Switzerland.

Inbar, Anna \& Leon Shor (forthcoming). Covert negation in Israeli Hebrew: Evidence from co-speech gestures? Journal of Pragmatics.

Ford, Cecilia E., Fox, Barbara A. \& Sandra A. Thompson (2002). Constituency and the grammar of turn increments, in: Ford, C.E., Fox, B.A. and Thompson, S.A. (eds), The language of turn and sequence, New York: Oxford University Press, 1438.

König, Ekkehard (1991). The meaning of focus particles: A comparative perspective (Theoretical Linguistics), London \& New York: Routledge.

Lakoff, George \& Mark Johnson (2008). Metaphors we live by. University of Chicago press.

Lehmann, Christian (1995). Thoughts on Grammaticalization, München/Newcastle: LINCOM EUROPA.

Norrick, Neal R. (2011). Interjections, in: Andersen, G. and Aijmer, K. (eds), Pragmatics of Society, De Gruyter, 243-292.

Norrick, Neal R. (2014). Interjections, in: Aijmer, K. and Rühlemann, C. (eds), Corpus Pragmatics, 249-273.

Pajusalu, Renate (2008). Pragmatics of quantifiers: The case of Estonian kõik 'all', Journal of Pragmatics 40(11), 1950-1965.

Shor, Leon (forthcoming). Negation in Israeli Hebrew, Usage Based Studies in Modern Hebrew, Amsterdam: John Benjamins.

Traugott, Elizabeth C. (1995a). The role of the development of discourse markers in a theory of grammaticalization, 12th International Conference on Historical Linguistics, Manchester, August 1995. 
Traugott, Elizabeth C. (1995b). Subjectifcation in grammaticalization, in: Stein, D. and Wright, S. (eds), Subjectivity and Subjectivisation: Linguistic Perspectives, Cambridge: Cambridge University Press, 31-54.

Vanhove, Martine (Ed.). 2008. From Polysemy to Semantic Change: Towards a Typology of Lexical Semantic Associations. John Benjamins Publishing.

Wang, Huayun \& Daogen Cao (2014). Demonstrative interjections in Huangxiao cluster of Jianghuai Mandarin, Journal of Chinese Linguistics 42(2), 267-308.

Wharton, Tim (2003). Interjections, language, and the 'showing/saying' continuum, Pragmatics \& Cognition 11, 39-91.

Wilkins, David (1992). Interjections as deictics, Journal of Pragmatics 18, 119-158.

Wilkins, David (1995). Expanding the traditional category of deictic elements: Interjections as deictics, in: Duchan, J. F., Bruder, G. A. and Hewitt, L. E. (eds), Deixis in narrative: A cognitive science perspective, Hillsdale, NJ: Erlbaum, 359-386. 